\title{
Epidermal Growth Factor Receptor Regulates Normal Urothelial Regeneration
}

\author{
Ahmad Daher, Willem I. de Boer, Ahmed El-Marjou, Theodorus van der Kwast, \\ Claude C. Abbou, Jean-Paul Thiery, François Radvanyi, and Dominique K. Chopin \\ INSERM EMI 03.37 (AD, CCA, DKC), Centre de Recherches Chirurgicales, Faculté de Médecine, Université de Paris \\ 12, Créteil, and UMR 144 CNRS (AE-M, J-PT, FR), Institut Curie, Paris, France; and Departments of Pulmonary \\ Medicine (WIdB) and Pathology (TvdK), Erasmus University, Rotterdam, The Netherlands
}

\begin{abstract}
SUMMARY: Members of the epidermal growth factor (EGF) family and their receptors are involved in many cellular processes, including proliferation, migration, and differentiation. We have previously reported that these growth factors are expressed and have specific regulatory functions in an organ-like culture model of normal human urothelial cells. Here, we used this model to investigate the involvement of EGF receptor (EGFR) in human urothelial regeneration. Three 4-mm-diameter damaged areas were made in confluent normal human urothelial cell cultures with a biopsy punch. Regeneration was measured, on fixed stained cultures, with an image analyzer, at 4, 24, and 48 hours after injury. Cell proliferation was assessed by 5-bromo-2-deoxyuridine incorporation. To identify EGF family factors potentially involved in the healing process, we studied the effect of these factors on damaged confluent cultures and the level of expression of mRNAs extracted from these cultures. EGFR inhibition of the proliferation and migration of urothelial cells was tested with (1) a specific tyrosine kinase inhibitor (AG1478) and (2) a blocking anti-EGFR antibody (LA22). Exogenously added amphiregulin, EGF, transforming growth factor- $\alpha$ and heparin-binding EGF (HB-EGF) stimulated urothelial regeneration. The damaged areas were repaired by regrowth within 48 hours. Both AG1478 and LA22 inhibited the repair (by $50 \%$ and $30 \%$, respectively), as well as proliferation and migration. This regeneration was accompanied by increased HB-EGF mRNA expression in cultures of cells from four of six subjects, but no corresponding change in EGFR protein level was observed. These results indicate that the EGFR signaling pathway is involved in urothelial regeneration. Our data support an autocrine role of HB-EGF in this process and suggest that the EGFR pathway is a potential therapeutic target for modulating urothelial cell proliferation. (Lab Invest 2003, 83:1333-1341).
\end{abstract}

$T$ he mammalian urine collection system, comprising the renal pelvis, ureter, bladder, and urethra, is lined by a multilayered transitional epithelium commonly referred to as the urothelium. The bladder and ureteral urothelium consist of five to six cell layers, comprising a basal cell layer, three or four intermediate cell layers, and a superficial cell layer composed of highly differentiated umbrella cells (Jost et al, 1989). Urothelial cell turnover is extremely low under normal conditions (Martin, 1972) but is increased after exposure to cytotoxic agents (Simeonova et al, 2000) and bacteria (Uchida et al, 1989) and also during tumorigenesis (Davis et al, 1984) and wound healing (Edlich and London, 1996). Bladder catheterization, cystoscopy fulguration, laser traumatisms, and irradiation, procedures commonly used in the management of patients with bladder cancer, initiate a complex sequence of events that culminates in wound repair (Cooper and See, 1992). Wound repair requires a precise coordination of cell proliferation, migration,

DOI: 10.1097/01.LAB.0000086380.23263.52

Received April 17, 2003.

Address reprint requests to: Dr. D. Chopin, INSERM EMI 03.37, Centre de Recherches Chirurgicales, Faculté de Médecine, 8 Rue du Général Sarrail, 94000 Créteil Cedex, France.E-mail: chopin@univ-paris12.fr and differentiation, as well as extracellular matrix synthesis and tissue remodeling.

The molecular mechanisms that regulate normal tissue repair are not fully understood, but growth factors, acting through autocrine or paracrine pathways, play an important role. They can be synthesized and secreted by a variety of tissues in vivo, including urothelium (Lau et al, 1988; Messing and Reznikoff, 1987; Noguchi et al, 1990). Enhanced expression of growth factors, especially those belonging to the epidermal growth factor (EGF) family and receptors, has been reported during wound healing, suggesting their involvement in this process (Abe et al, 1997; Ashcroft et al, 1997; Baskin et al, 1997; de Boer et al, 1994b, 1996; Konturek et al, 1996; Stoscheck et al, 1992).

The EGF family includes, in addition to EGF, transforming growth factor- $\alpha$ (TGF- $\alpha$ ), heparin-binding EGF (HB-EGF), amphiregulin (AR), betacellulin, heregulin (HRG), epiregulin, and neuregulin. All these proteins act on cells via specific tyrosine kinase transmembrane receptors (EGFR/c-erbB-1, HER2/neu/cerbB-2, HER3/c-erbB-3, and HER4/c-erbB-4). The growth factors bind to the extracellular domain of the corresponding receptors, inducing receptor dimerization, followed by activation of the intracellular kinase domain and its autophosphorylation (Schlessinger 
and Ullrich, 1992). This initiates signal transduction and a biologic response by the target cell.

Several studies point to the involvement of EGF-like growth factors and EGFR in epithelial repair. In vivo studies have shown overexpression of EGFR and TGF- $\alpha$ mRNA during rat bladder wound repair (Baskin et al, 1997). Likewise, a high concentration of TGF- $\alpha$ protein was detected in urine rat bladder after urothelial trauma (Cooper and See, 1992). Colocalization of proliferating cell nuclear antigen and EGFR was observed in the margins of human gastric ulcers, suggesting the involvement of EGFR in cell proliferation during wound healing (Abe et al, 1997).

Functional studies show that exogenous EGF enhances in vivo wound healing in damaged guinea pig airways (Kim et al, 1998), rabbit cornea (Nishida et al, 1990), and epidermis of pigs (Breuing et al, 1997; Brown et al, 1989; Schultz et al, 1991) and humans (Brown et al, 1989). Evidence of the direct involvement of TGF- $\alpha$ in epithelial repair was reported by Kobayashi et al (1996), who found that TGF- $\alpha$ accelerated wound repair in a rabbit gastric cell culture.

Messing et al (1987) demonstrated the EGFR pathway signaling in normal and malignant urothelium. Other authors have confirmed the existence of this autocrine EGFR loop during repair of cutaneous (Barnard et al, 1994; Stoll et al, 1997; Stoscheck et al, 1992), bronchial (Davies et al, 1999; Puddicombe et al, 2000), and corneal epithelium (Beuerman and Thompson, 1992; Zieske et al, 2000). Moreover, HB-EGF is reported to play an important role in autocrine growth of gastric epithelial cells (Miyazaki et al, 1996), urothelial cells (Freeman et al, 1997), and keratinocytes (Hashimoto et al, 1994). Together with AR, HB-EGF enhanced skin culture repair (Stoll et al, 1997). This autocrine loop was also activated by TGF- $\alpha$ and AR when normal human bronchial epithelial cells were seeded in vitro (Tsao et al, 1996). The role of EGF family members in human urothelial wound healing has not been thoroughly explored.

We have previously reported that EGF and EGFR are expressed in an organ-like culture model of normal human urothelial cells (de Boer et al, 1996). Here, we used this model to investigate the involvement of EGF-like growth factors and the EGFR autocrine loop in human urothelial wound healing after acute injury.

\section{Results}

Bladder outgrowth covered the membrane after 20 days. It reached confluence after 25 days, and no significant difference were found between biopsy specimens, of different embryologic origin, derived from the trigone or the dome. However, biopsy specimens from the ureter reached confluence on the porous membrane by 21 days. We therefore performed our studies on material derived from ureter biopsy specimens.

Photomicrographs of cultures stained by immunocytochemistry showed gradual closure of the punch areas after 4 hours (Fig. 1A), 24 hours (Fig. 1B), and 48 hours (Fig. 1C). Re-epithelialization of these holes was
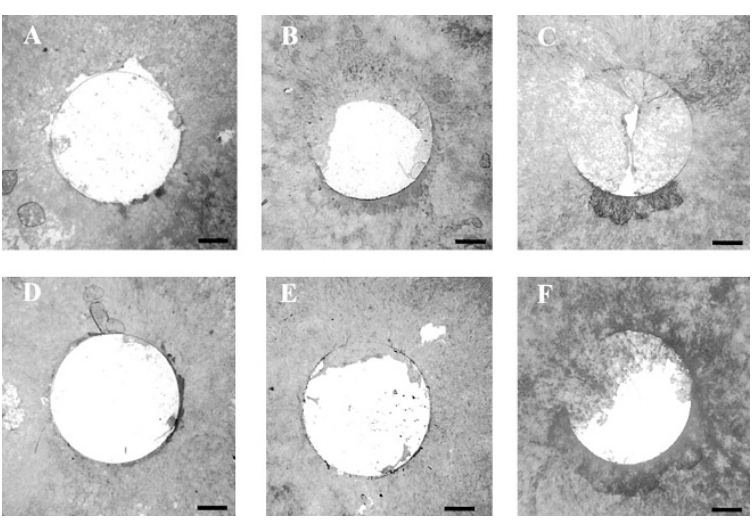

Figure 1.

Microphotographs of urothelial regeneration on fixed-stained membranes (labeled cells are marked by anti-Ck18 antibody), at regular time intervals. Serum-free medium alone (A: 4 hours; B: 24 hours; and C: 48 hours) or with the AG1478 inhibitor (D: 4 hours; E: 24 hours; and F: 48 hours) (bar $=1 \mathrm{~mm}$ ).

complete after 48 hours in serum-free medium, as shown by measuring the regenerated surface areas (Fig. 1C).

Because EGF-like growth factors are thought to be expressed in epithelial regeneration, expression of mRNA of the EGF family members and their receptors was semiquantified by RT-PCR between 4 and 24 hours after injury. The confluent urothelia used in these experiments were damaged with cross-parallel wounds in an attempt to maximize the number of cells entering "regeneration mode." Figure 2 shows the kinetics of HB-EGF (A), AR (B), and TGF- $\alpha(C)$ mRNA expression in cultures from one patient at $4,8,12$, and 24 hours before and after injury. In comparison to undamaged urothelial cultures, only HB-EGF mRNA expression was enhanced in cultures prepared from four of six patients at $4,8,12$, and 24 hours after injury (Fig. 2A).

We also investigated the effect of AR, EGF, TGF- $\alpha$, and HB-EGF on urothelial regeneration. In comparison with serum-free medium, the EGF family members, EGF (20 ng/ml), TGF- $\alpha$ (20 ng/ml), AR (100 ng/ml), and HB-EGF $(20 \mathrm{ng} / \mathrm{ml})$, significantly stimulated urothelial regeneration at $3,20,27,43$, and 47 hours after injury. HRG- $\alpha$ (150 ng/ml) had no effect on this cell mechanism (Fig. 3).

To inhibit the growth factor pathway thought to be essential for bladder wound healing, AG1478, a specific EGFR inhibitor, was added to cultures in serumfree medium immediately after punches were made and images were recorded after 4 hours (Fig. 1D), 24 hours (Fig. 1E), and 48 hours (Fig. 1F). Inhibition of re-epithelialization by AG1478 was observed at 24 hours (Fig. 1E) and 48 hours (Fig. 1F) after injury, as compared with identical control cultures without AG1478 (Fig. 1, B and C).

Urothelial regeneration was significantly inhibited by AG1478 (approximately 50\%) at 24 hours and 48 hours after injury but not at 4 hours (Fig. 4). This regeneration was less inhibited $(25 \%)$ in the presence of additional fibroblast growth factor-1 (FGF-1; 20 
(A)

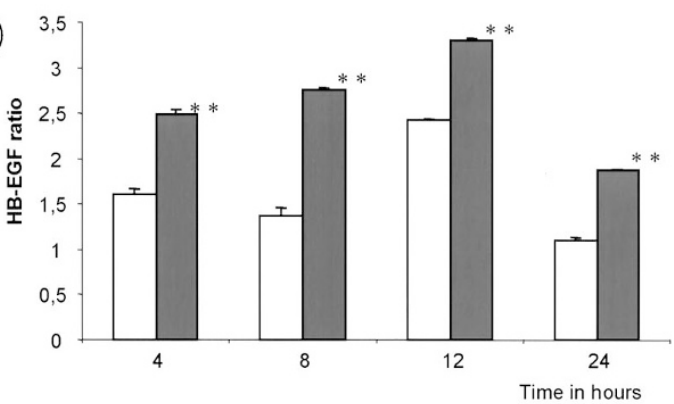

(B)

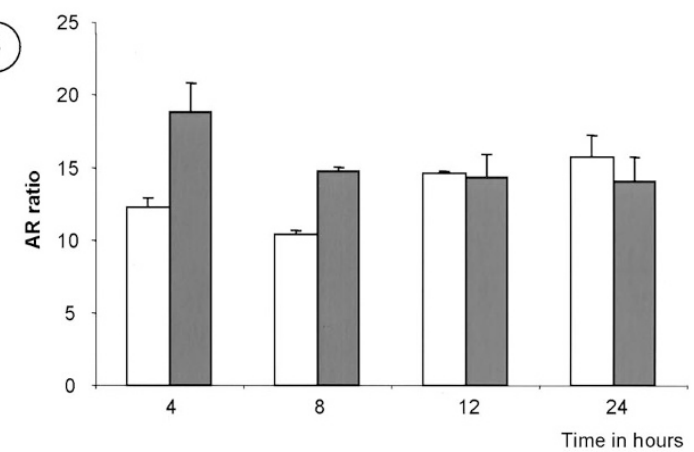

(C)

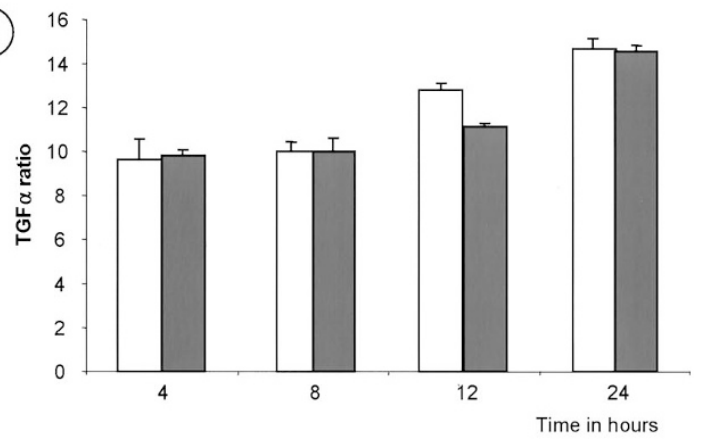

Figure 2.

Expression of heparin-binding EGF (HB-EGF) (A), amphiregulin (AR) (B), and transforming growth factor- $\alpha$ (TGF- $\alpha$ ) (C) mRNA measured by semiquantitative RT-PCR in intact (white bar) and regenerating urothelium (gray bar) in culture. The expression is given as the ratio of the level of mRNA over that of TBP mRNA $\left({ }^{* *} p<0.0001\right)$.

$\mathrm{ng} / \mathrm{ml}$ ). AG63, an irrelevant structural analog of AG1478, had no effect on the repair process (Fig. 4). Re-epithelialization was also significantly inhibited by the neutralizing anti-EGFR antibody (by approximately $30 \%$ ) in serum-free medium at 24 and 48 hours after injury. An irrelevant control antibody had no effect on the repair process (Fig. 5).

Cell proliferation was also studied in terms of 5-bromo-2-deoxyuridine (BrdU) incorporation. Cell proliferation was first detected at 4 hours after injury. At 24 hours the number of proliferating cells increased markedly near the regeneration zone. To investigate the location of proliferating cells, we examined the damaged zone (DZ; the inside of the punch hole); the peri-damaged zone (PDZ; at the edges of the holes), and the peripheral zone (PZ; a zone distant from the holes) (Fig. 6A). Marked cell labeling was stronger in the PDZ than in the DZ at all time points (Fig. 6B).

The percentage of labeled cells in the $P Z$ remained stable during re-epithelialization (Fig. 7, A to C). Cell

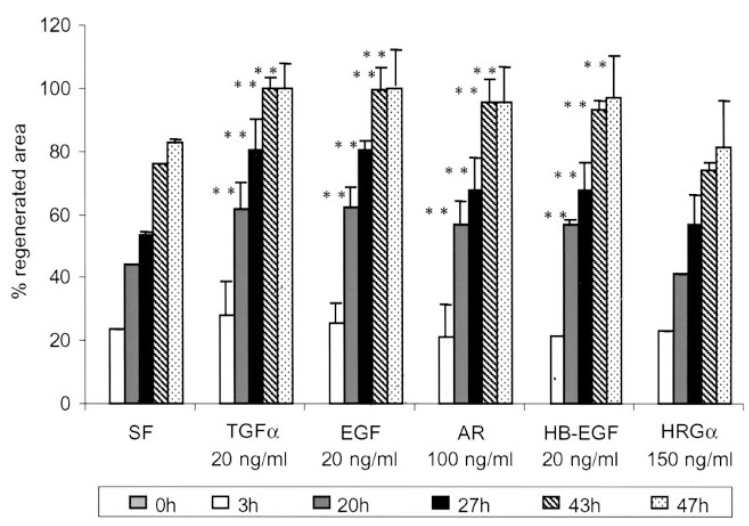

Figure 3.

Percentage of urothelial regeneration in the presence of the EGF family members: TGF- $\alpha(20 \mathrm{ng} / \mathrm{ml})$, EGF $(20 \mathrm{ng} / \mathrm{ml})$, AR $(100 \mathrm{ng} / \mathrm{ml})$, HB-EGF $(20$ $\mathrm{ng} / \mathrm{ml})$, and heregulin- $\alpha$ (HRG- $\alpha)(150 \mathrm{ng} / \mathrm{ml})$ at $0,3,20,27,43$, and 47 hours after injury.

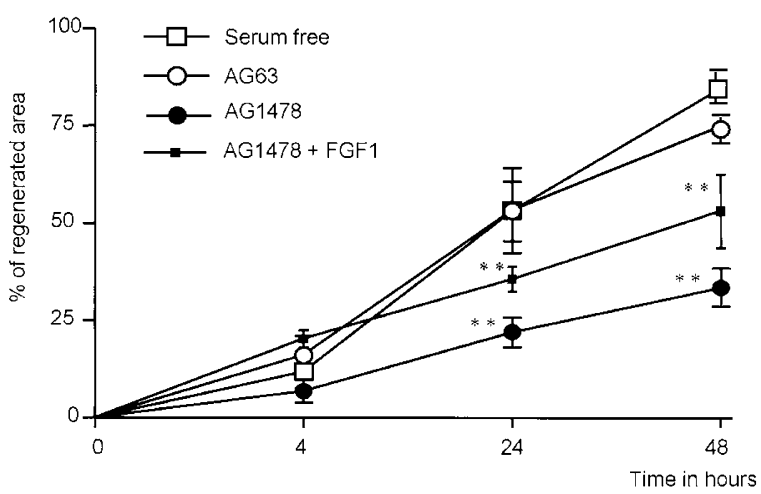

Figure 4.

Percentage of urothelial regeneration in serum-free medium $(\square)$, with AG63

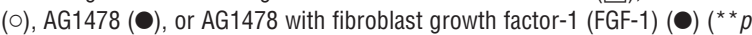
$<0.0001)$ at different time intervals.

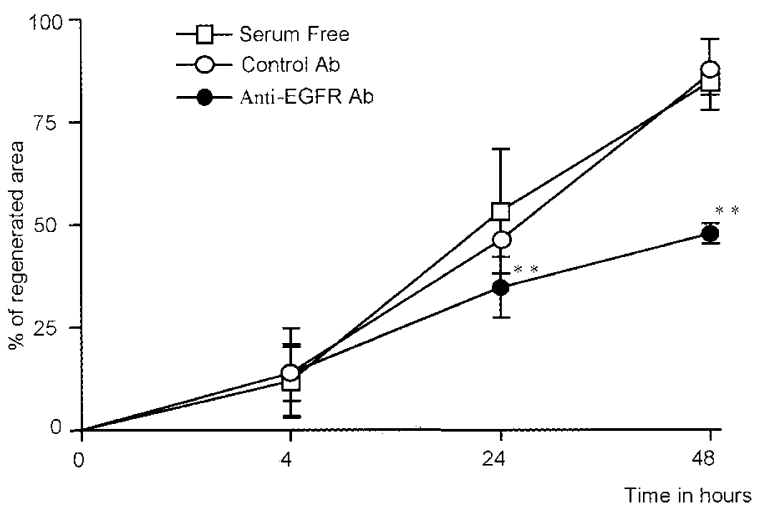

Figure 5.

Percentage of urothelial regeneration in serum-free medium $(\square)$, with control antibody (०) or anti-EGFR antibody $(\bullet)\left({ }^{* \star} p<0.0001\right)$.

proliferation was significantly enhanced in both the PDZ and DZ, relative to the PZ, at 4,24 , and 48 hours after injury (Fig. 7A). This increase was abolished by AG1478, with the percentage of labeled cells returning to baseline values in the different zones (Fig. 7B). AG63, the inactive structural analog of AG1478, did 

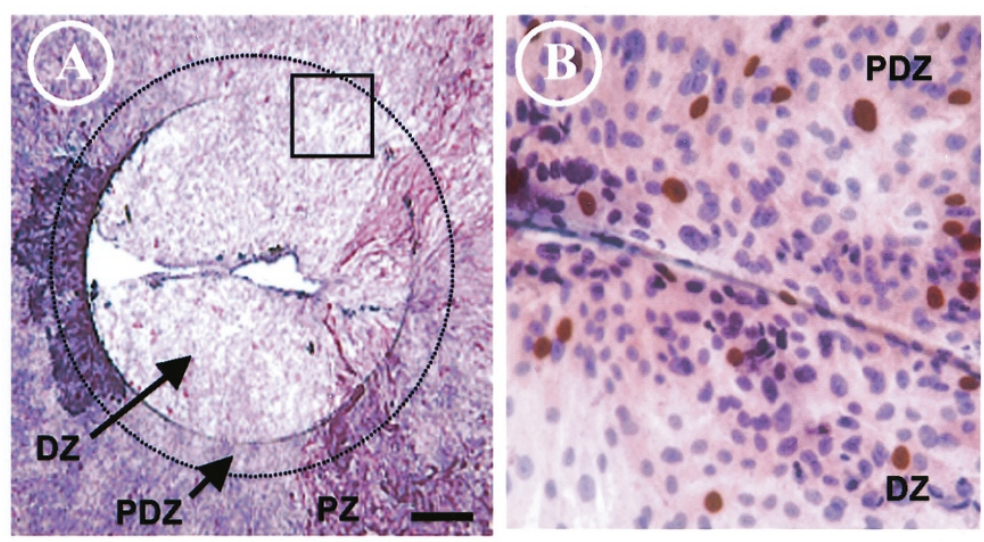

Figure 6.

Microphotograph of different proliferation zones observed at 48 hours after injury $(D Z=$ damaged zone; $P D Z=$ peri-damaged zone; and $P Z=$ peripheral zone $)$ (bar $=1 \mathrm{~mm})(\mathrm{A})$. Magnification focused on the cell proliferation in PDZ and DZ [labeled nucleus is marked by anti-5-bromo-2-deoxyuridine (anti-BrdU) antibody] (B).

(A)

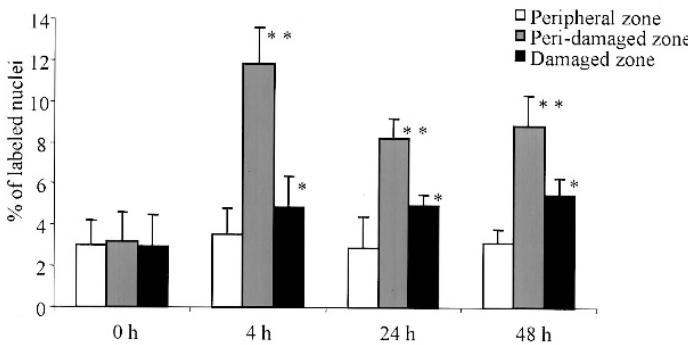

(B)

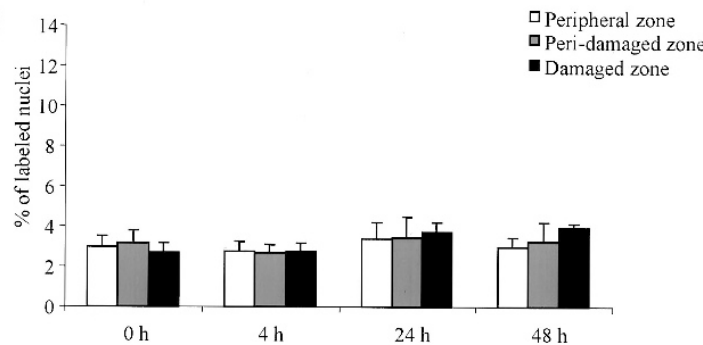

(C)

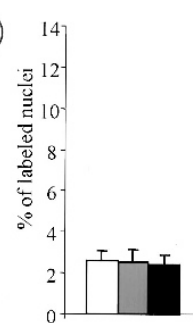

$0 \mathrm{~h}$

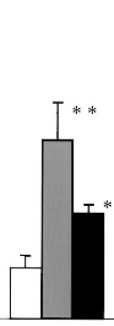

$4 \mathrm{~h}$

$48 \mathrm{~h}$

पPeripheral zone Peri-damaged zone Damaged zone

Figure 7.

Percentage of BrdU incorporation in serum-free medium (A), with AG1478 (B) or with $A G 63+(C)$ at $0,4,24$, and 48 hours after injury, in three different zones: PZ, PDZ, and DZ ( $\left.{ }^{\star} p=0.001 ;{ }^{*}{ }^{\star} p<0.0001\right)$.

not affect the percentage of labeled cells (Fig. 7C). Proliferation was stronger in the PDZ than in the DZ at all time points in the absence of AG1478 but not in its presence (Fig. 7, A to C).

The anti-EGFR antibody reduced the percentage of proliferating cells in the PDZ at all times after injury (Fig. 8, A and B). Cell proliferation was less markedly reduced by this antibody in the DZ than in the PDZ

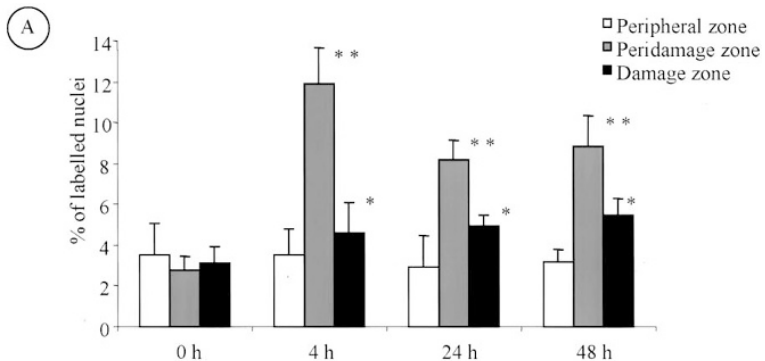

(B)

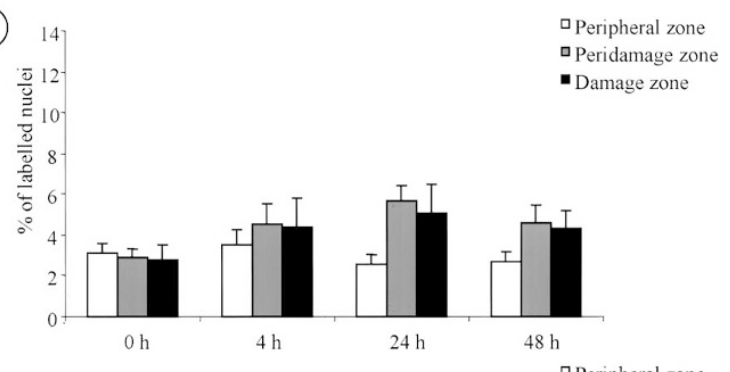

(C)

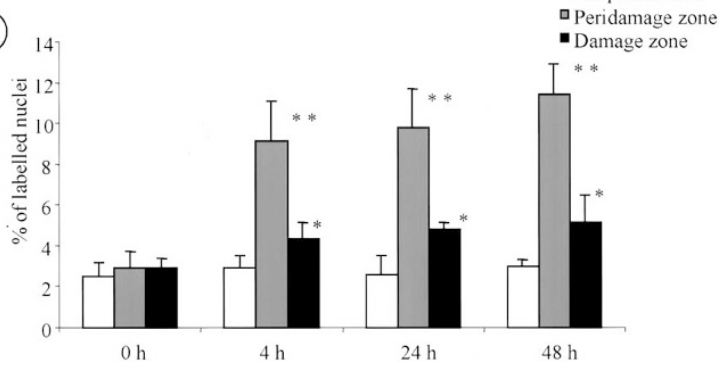

Figure 8.

Percentage of BrdU incorporation in serum-free medium (A), with anti-EGFR antibody (B) or with control antibody (C) at 0, 4, 24, and 48 hours after injury, in three different zones: PZ, PDZ, and DZ $\left({ }^{\star} p=0.001 ;{ }^{\star \star} p<0.0001\right)$.

(Fig. 8, A to C). The control antibody did not affect the percentage of proliferating cells (Fig. 8, A and C).

Finally, Western blot analysis showed no change in EGFR protein expression in normal or damaged cultures, regardless of treatment with AG1478 (Fig. 9). The representative photograph of one patient shows the $170-\mathrm{kDa}$ EGFR protein in comparison to the A431 


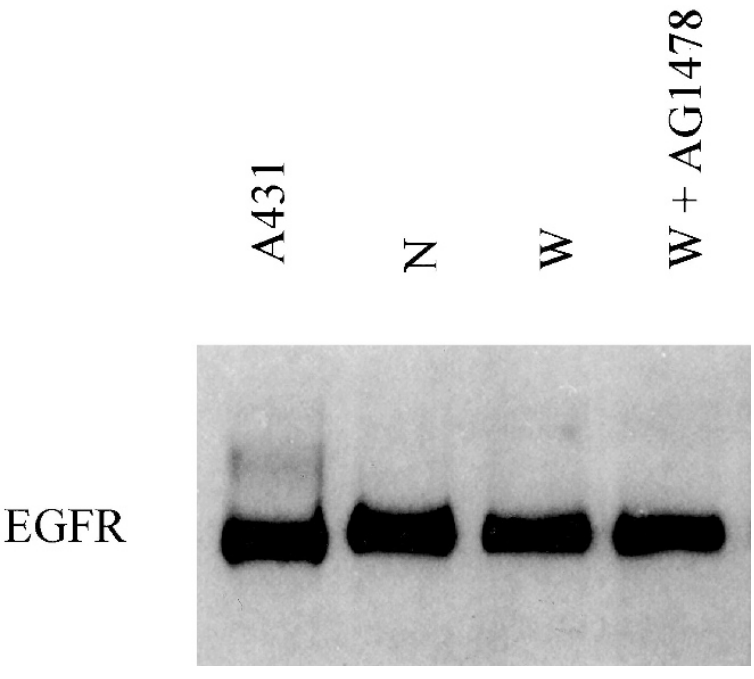

Figure $\mathbf{9}$.

EGFR protein detection in Western blot for one patient in normal intact $(M)$ and wounded urothelium without ( $W$ or with AG1478 (W+AG1478). A431 cells served as a positive control for EGFR expression.

cell extract (a squamous human carcinoma cell line overexpressing EGFR).

\section{Discussion}

During wound repair, EGF family members and their receptor EGFR are strongly expressed in several epithelia, including that of skin (Ashcroft et al, 1997; Higashiyama et al, 1992), cornea (Beuerman and Thompson, 1992), bronchus (Davies et al, 1999), and stomach (Abe et al, 1997; Konturek et al, 1996; Liu et al, 1998). The involvement of an EGFR autocrine loop in epithelial wound repair has been demonstrated in skin (Stoll et al, 1997), bronchus (Puddicombe et al, 2000), and cornea (Zieske et al, 2000).

Baskin et al (1997) detected stronger expression of TGF- $\alpha$ and EGFR mRNA in wounded than in intact urothelium. Cooper and See (1992) noted high urinary concentrations of TGF- $\alpha$ after different types of bladder insult. No direct correlation was found between the expression of these proteins and wound healing in these latter two studies. Freeman et al (1997) demonstrated that HB-EGF stimulated the growth of human urothelial cells in vitro.

To better understand the role of this family in urothelial regeneration, we investigated the mRNA expression of EGF family growth factor members and receptors by using a semiquantitative $\mathrm{RT}$-PCR technique. The confluent urothelia used in these experiments were damaged with cross-parallel wounds in an attempt to maximize the number of cells entering regeneration mode. HB-EGF mRNA was increased in cultures of cells from four of the six patients tested. No significant changes in transcript levels of the other EGF family members or EGFR were noticed. This supports the involvement of HB-EGF in urothelial cell growth (Freeman et al, 1997).

To further explore the role of the EGF family members, we tested the exogenous effect of TGF- $\alpha$, EGF,
$A R$, and HB-EGF on urothelial regeneration. These growth factors stimulate urothelial regeneration, and it seems that they play a role. However, $\mathrm{HRG}-\alpha$, which is not a ligand of EGFR, had no effect in this cell mechanism. These factors were added to the serumfree medium once daily. The concentrations were previously found to be optimal for stimulation of proliferation of urothelial cells (de Boer et al, 1997). HB-EGF has been implicated in the growth of an intestinal epithelial cell line (Barnard et al, 1994), in human keratinocytes (Hashimoto et al, 1994; Stoll et al, 1997), and in epithelial rat cornea repair (Zieske et al, 2000). In accordance, our data on HB-EGF showing a stimulated regeneration supported the idea on the role of HB-EGF.

The EGF family members activate the intracellular kinase domain of their receptor and its autophosphorylation, initiating a signal transduction into the cell and a biologic response by the cell. Recently, various inhibitors targeting these factors or receptors have become available. In this study, we used AG1478 (an EGFR tyrosine kinase inhibitor) and LA22 (a blocking anti-EGFR $\mathrm{mAb}$ ) to inhibit this growth factor pathway thought to be essential for bladder wound healing. Tyrphostin AG1478 blocks activation of the receptor kinase domain by competition with ATP and markedly inhibits EGFR transmembrane signaling. In our study, AG1478 inhibited urothelial regeneration and abolished cell proliferation in both the damaged area and the surrounding area, suggesting that the EGFR pathway is involved in urothelial wound repair. AG63, an irrelevant structural analog of AG1478, had no effect. However, AG1478 did not fully inhibit urothelial regeneration, suggesting that other growth factors and receptors also play a role. Our study supports this hypothesis by demonstrating that urothelial regeneration was less inhibited in the presence of the exogenous FGF-1 growth factor. FGF-1 was chosen as a model ligand for another non-EGFR-related class of tyrosine kinase growth factor receptors.

Zieske et al (2000) reported that AG1478 concentrations between 10 and $30 \mu \mathrm{M}$ inhibited corneal epithelial cell migration, whereas Puddicombe et al (2000) reported that $1 \mu \mathrm{M}$ AG1478 was already sufficient to inhibit repair in lung epithelial cultures. We also used this latter concentration, to avoid cell toxicity, and obtained the same degree of growth inhibition (50\%) as that reported by Puddicombe et al (2000). These inhibitors were added to the serum-free medium after injuries were made and once per day.

Use of a blocking anti-EGFR antibody confirmed the involvement of the EGFR pathway in urothelial regeneration. This antibody (LA22) blocks growth factor binding to the receptor, thereby inhibiting receptor activation and signal transduction. In our model, we found a significant inhibition of regeneration and cell proliferation, in both the punch hole and the neighboring area, at 4, 24, and 48 hours after injury (approximately $30 \%$ inhibition). A control antibody had no effect on either parameter. This is in agreement with results obtained by Stoll et al (1997) on growth factor inhibition in skin organ culture by an anti-EGFR anti- 
body (mAb 225) (approximately 50\% inhibition) and by Tsao et al (1996) on human bronchial epithelial cell growth inhibition by EGFR-neutralizing mAbs (LA1 and 528) (approximately 40\% inhibition).

The highest percentage of proliferating cells was found around the punch hole, as early as 4 hours after injury. This may be explained by the presence of mitogenic factors that were rapidly secreted and synthesized after injury and supports our hypothesis on the role of the EGF family members. Zones distant from the site of injury showed no increase in cell proliferation. Proliferation remained low in the punch damaged area during re-epithelialization. Thus, wound closure may have been more a result of cell migration than of cell proliferation in the DZ.

Western blot analysis showed no change in EGFR protein expression in normal or injured cultured urothelium, with or without tyrosine kinase inhibition. This is in keeping with data from Stoll et al (1997) and Wilson et al (1999), who respectively reported no change in EGFR expression in damaged human skin or mouse corneal epithelium. In contrast, an increase in EGFR protein expression has been reported after corneal epithelial wounding (Beuerman and Thompson 1992), in ulcerated gastric mucosa (Abe et al, 1997; Konturek et al, 1996), and during in vitro repair of bronchial epithelium (Puddicombe et al, 2000). Our results suggest that wound repair mechanisms act via growth factor ligand expression and through EGFR signal transduction but not via increased EGFR protein expression.

\section{Conclusion}

Our data demonstrate that EGFR plays a key role in transmembrane signal transduction during urothelium regeneration and that this effect is mediated by an autocrine loop that may involve HB-EGF. These experiments contribute to our understanding of the biologic functions of EGF family growth factors in wound healing. They also point to novel therapeutic strategies for enhancing, via the EGFR pathway, the healing of burns, other trauma, diabetic ulcers, and tissue graft donor sites. The same strategies might also be used in bladder reconstruction and replacement surgery. Finally, these data may have implications for pharmacologic control of tumor growth.

\section{Materials and Methods}

\section{Chemicals}

Culture reagents and plastic materials were purchased from the following sources: a mixture of DMEM and Ham's F12 (Gibco Life Technologies BRL, Eragny, France); EGF family growth factors and FGF-1 (R\&D Systems Europe, Lille, France); Multiwell cell culture insert plates and Cyclopore $0.45-\mu \mathrm{m}$ polyethylene terephthalate membrane inserts (Falcon, Becton Dickinson, Le Pont de Claix, France); human collagen IV (Fluka, Buchs, Switzerland); and AG1478 and AG63 (Calbiochem; San Diego, California). Immunohistochemical reagents were obtained as follows: RGE53 and RCK108 antibodies raised against cytokeratins 18 and 19, respectively, and anti-BrdU antibody were kindly provided by Professor F. C. S. Ramaekers (Department of Molecular Cell Biology and Genetics, University of Maastricht, The Netherlands); secondary antibodies (alkaline phosphatase-conjugated swine anti-rabbit antibody and peroxidase-conjugated rabbit anti-mouse antibody) were from Dako (Glostrup, Denmark); polyclonal anti-EGFR antibody was from Santa Cruz Biotechnology (TEBU, Le Peray en Yvelines, France); neutralizing anti-EGFR antibody was from Upstate Biotechnology (Euromedex, Souffelweyersheim, France); and Immumount was from Shandon (Pittsburgh, Pennsylvania).

\section{Culture Substrate}

Type IV collagen was dissociated in acetic acid and diluted in HBSS (Gibco Life Technologies BRL). Cyclopore membranes (25 mm, pore diameter $0.45 \mu \mathrm{m}$ ) were covered with $2.5 \mu \mathrm{g} / \mathrm{cm}^{2}$ type IV collagen and incubated for at least 1 hour in a humidified atmosphere at $37^{\circ} \mathrm{C}$. The membranes were then postcoated with $0.01 \%$ BSA, washed with water, and dried before bladder explant deposition.

\section{Ureter and Bladder Explant Culture}

Fresh normal urothelium was obtained from nephroureterectomy samples in our Urology Department (Henri Mondor Hospital, Créteil, France). The mucosal cell layer was stripped from the muscle layer and submucosa under an operating microscope (OPMI-6; Statis Standard $f=125$, ZEISS, Germany) and then spread on a coated Cyclopore membrane with the basement membrane facing the support. The membranes were placed in 6-well tissue culture plates, and the compartments were filled with standard culture medium (refreshed every second day). The standard medium consisted of a 1:1 mixture of DMEM and Ham's F-12 medium, supplemented with 10\% heatinactivated FCS, $5 \mu \mathrm{g} / \mathrm{ml}$ insulin and $5 \mu \mathrm{g} / \mathrm{ml}$ transferrin, $50 \mathrm{~nm}$ hydrocortisone, $5 \mathrm{ng} / \mathrm{ml}$ sodium selenite, $10 \mu \mathrm{M}$ HEPES, and $100 \mathrm{U} / \mathrm{ml}$ penicillin/streptomycin. Cultures were incubated at $37^{\circ} \mathrm{C}$ in humidified air containing $5 \% \mathrm{CO}_{2}$.

\section{Culture Medium Additives}

Growth factors were added to the serum-free culture medium at final concentrations of $20 \mathrm{ng} / \mathrm{ml}$ (FGF-1, HB-EGF, EGF, TGF- $\alpha$ ), $100 \mathrm{ng} / \mathrm{ml}(\mathrm{AR})$, or $150 \mathrm{ng} / \mathrm{ml}$ (HRG- $\alpha$ ) once daily. The anti-EGFR antibody (LA22) and tyrosine kinase inhibitor (AG1478) were added to the serum-free culture medium, after injuries were made and once daily, at final concentrations of 2 $\mu \mathrm{g} / \mathrm{ml}$ and $1 \mu \mathrm{M}$, respectively. AG1478 and AG63, both soluble in dimethyl sulfoxide, were diluted in serumfree medium standard medium supplemented with 4 $\mu \mathrm{M}$ spermine, $4 \mu \mathrm{M}$ spermidine, and $10 \mu \mathrm{M}$ putrescine. 


\section{BrdU Incorporation}

At various times after injury, cultures were incubated with $40 \mu \mathrm{g} / \mathrm{ml} \mathrm{BrdU}$ in serum-free medium for 2 hours and then rinsed with PBS pH 7.2 and fixed with $70 \%$ ethanol for at least 1 hour. BrdU incorporation was revealed by immunocytochemistry using an anti-BrdU $\mathrm{mAb}$, and the percentage of BrdU-positive nuclei was counted in 10 random areas of $1 \mathrm{~mm}^{2}$ each. The areas were selected from the DZ, the PDZ, and the PZ (Fig. 4).

\section{Immunocytochemistry}

Cultures were immunostained as described elsewhere (de Boer et al, 1994a). Briefly, cultures were first fixed with $70 \%$ ethanol, before incubation with the primary anti-BrdU antibody, and then treated with $2 \mathrm{~N}$ hydrochloric acid and borax buffer ( $\mathrm{pH}$ 8.5). Chain-specific cytokeratins and BrdU labeling was detected with appropriate dilutions of the respective primary mouse $\mathrm{mAb}$ in a conjugated immuno-enzymatic assay. The chromogens were 3,3'-diaminobenzidine and the diazonium salt Fast Red Violet LB, with naphthol AS-MX phosphate as coupling agent (Sigma). Finally, the membranes were counterstained with Mayer's blue hemalum and mounted in Immumount under coverslips.

\section{Morphometry}

Using a biopsy punch, three demarcated, damaged areas (4-mm diameter) were made in confluent urothelial cell cultures. The surface area of regeneration was calculated in square millimeters and expressed as a percentage of the maximal area of outgrowth (measured at 48 hours). The regenerated surface area $\left(\mathrm{mm}^{2}\right)$ was measured after 4, 24, and 48 hours on ethanol-fixed immunocytochemistry-stained membranes with an Olympus microscope at low magnification coupled to a computer-assisted image analysis system (Measure, ClaraVision, France).

\section{RNA Analysis}

After making a series of cross-parallel wounds on the confluent urothelial culture, total RNA was extracted with Trizol (Gibco Life Technologies BRL) at approximately 12 hours (before wound closure) and used as the template for first-strand cDNA synthesis by random priming with reverse transcriptase. mRNA extracted from urothelium scraped from normal ureters was used as a Day 0 control. Semiquantitative PCR was performed with $1 \mu \mathrm{g}$ of cDNA as described elsewhere (Diez de Medina et al, 1997; Radvanyi et al, 1993). The PCR-amplified products were subjected to electrophoresis in $8 \%$ polyacrylamide gels. Signals were quantified with a Molecular Dynamics 300 Phospholmager (Sunnyvale, California). The 5'-to-3' sense (S) and antisense (AS) primer pair sequences were as follows: EGFR:

CTTGAAGGCTGTCCAACGAAT (S), GTGCGCTTCCGAACGATGT (AS); TGF- $\alpha$ : CCAGATTCCCACACT-
CAGTT (S), TCACAGCGTGCACCAACGTA (AS); AR: CTGTGAGTGAAATGCCTTCTAG (S), GGGGCTTAACTACCTGTTCA (AS); HB-EGF: ACAAGGACTTCTGCATCCAT (S), GACACCTCTCTCCATGGTAAC (AS); and TBP: AGTGAAGAACAGTCCAGACTG (S), CCAGGAAATAACTCTGGCTCAT (AS). Experimental optimal density values were compared with those of the ubiquitous transcription factor TATA binding protein (TBP) (Peterson et al, 1990), used as an internal control.

\section{Western Blotting}

At 12 hours after injury, cell lysates were prepared by adding $250 \mu$ l of lysis buffer $(0.599 \mathrm{~g} / \mathrm{L}, 0.1 \mathrm{M}$ EDTA, $1 \%$ Nonidet P-40, $50 \mathrm{~mm}$ p-nitrophenyl p-guanidinobenzoate, $25 \mu \mathrm{M}$ orthovanadate, and 50 mM sodium fluoride) and incubated for 10 minutes on ice. The lysate was clarified by centrifugation at $10,000 \times g$ for 10 minutes. The protein concentration was determined by the Bradford assay, and the supernatant was mixed with $2 \times$ Laemmli sample buffer. Total protein $(50 \mu \mathrm{g})$ was submitted to $7.5 \%$ SDSPAGE as described by Laemmli et al (1970). Proteins were transferred electrophoretically to Immobilon P membranes. The membranes were saturated with $3 \%$ gelatin, PBS-0.2\% Tween 20, and incubated with polyclonal anti-EGFR antibody; EGFR was visualized by enhanced chemiluminescence. The A431 cell line was used as control for EGFR content.

\section{Statistical Analysis}

All experiments were performed at least three times in duplicate. All data are given as the means of all experiments \pm SD. The significance of differences was determined using Student's $t$ test. Differences were regarded to be significant at $p<0.05$.

\section{References}

Abe S, Sasano H, Katoh K, Ohara S, Arikawa T, Noguchi T, Asaki S, Yasui W, Tahara E, Nagura H, and Toyota T (1997). Immunohistochemical studies on EGF family growth factors in normal and ulcerated human gastric mucosa. Dig Dis Sci 42:1199-1209.

Ashcroft GS, Horan MA, and Ferguson MW (1997). The effects of ageing on wound healing: Immunolocalisation of growth factors and their receptors in a murine incisional model. J Anat 190(Pt 3):351-365.

Barnard JA, Graves-Deal R, Pittelkow MR, DuBois R, Cook P, Ramsey GW, Bishop PR, Damstrup L, and Coffey RJ (1994). Auto- and cross-induction within the mammalian epidermal growth factor-related peptide family. J Biol Chem 269: 22817-22822.

Baskin LS, Sutherland RS, Thomson AA, Nguyen HT, Morgan DM, Hayward SW, Hom YK, DiSandro M, and Cunha GR (1997). Growth factors in bladder wound healing. J Urol 157:2388-2395.

Beuerman RW and Thompson HW (1992). Molecular and cellular responses of the corneal epithelium to wound healing. Acta Ophthalmol Suppl (202):7-12. 
Breuing K, Andree C, Helo G, Slama J, Liu PY, and Eriksson E (1997). Growth factors in the repair of partial thickness porcine skin wounds. Plast Reconstr Surg 100:657-664.

Brown GL, Nanney LB, Griffen J, Cramer AB, Yancey JM, Curtsinger LJ 3rd, Holtzin L, Schultz GS, Jurkiewicz MJ, and Lynch JB (1989). Enhancement of wound healing by topical treatment with epidermal growth factor. $\mathrm{N}$ Engl $\mathrm{J}$ Med 321:76-79.

Cooper CS and See WA (1992). The impact of iatrogenic urothelial trauma on urinary levels of transforming growth factor-alpha. J Urol 147:1647-1649.

Davies DE, Polosa R, Puddicombe SM, Richter A, and Holgate ST (1999). The epidermal growth factor receptor and its ligand family: Their potential role in repair and remodelling in asthma. Allergy 54:771-783.

Davis CP, Cohen MS, Gruber MB, Anderson MD, and Warren MM (1984). Urothelial hyperplasia and neoplasia: A response to chronic urinary tract infections in rats. J Urol 132:10251031.

de Boer WI, Houtsmuller AB, Izadifar V, Muscatelli-Groux B, Van der Kwast TH, and Chopin DK (1997). Expression and functions of EGF, FGF and TGFbeta-growth-factor family members and their receptors in invasive human transitionalcell-carcinoma cells. Int J Cancer 71:284-291.

de Boer WI, Rebel JM, Vermey M, de Jong AA, and van der Kwast TH (1994a). Characterization of distinct functions for growth factors in murine transitional epithelial cells in primary organotypic culture. Exp Cell Res 214:510-518.

de Boer WI, Schuller AG, Vermey M, and van der Kwast TH (1994b). Expression of growth factors and receptors during specific phases in regenerating urothelium after acute injury in vivo. Am J Pathol 145:1199-1207.

de Boer WI, Vermeij M, Diez de Medina SG, Bindels E, Radvanyi F, van der Kwast T, and Chopin D (1996). Functions of fibroblast and transforming growth factors in primary organoid-like cultures of normal human urothelium. Lab Invest 75:147-156.

Diez de Medina SG, Chopin D, El Marjou A, Delouvee A, LaRochelle WJ, Hoznek A, Abbou C, Aaronson SA, Thiery JP, and Radvanyi F (1997). Decreased expression of keratinocyte growth factor receptor in a subset of human transitional cell bladder carcinomas. Oncogene 14:323-330.

Edlich RF and London SD (1996). Wound repair: From ritual practice to scientific discipline. J Trauma 40:326-329.

Freeman MR, Yoo JJ, Raab G, Soker S, Adam RM, Schneck FX, Renshaw AA, Klagsbrun M, and Atala A (1997). Heparinbinding EGF-like growth factor is an autocrine growth factor for human urothelial cells and is synthesized by epithelial and smooth muscle cells in the human bladder. J Clin Invest 99:1028-1036.

Hashimoto K, Higashiyama S, Asada H, Hashimura E, Kobayashi T, Sudo K, Nakagawa T, Damm D, Yoshikawa K, and Taniguchi N (1994). Heparin-binding epidermal growth factor-like growth factor is an autocrine growth factor for human keratinocytes. J Biol Chem 269:20060-20066.

Higashiyama M, Hashimoto K, Takada A, Fujita K, Kido K, and Yoshikawa K (1992). The role of growth factor in wound healing. J Dermatol 19:676-679.

Jost SP, Gosling JA, and Dixon JS (1989). The morphology of normal human bladder urothelium. J Anat 167:103-115.
Kim JS, McKinnis VS, Nawrocki A, and White SR (1998). Stimulation of migration and wound repair of guinea-pig airway epithelial cells in response to epidermal growth factor. Am J Respir Cell Mol Biol 18:66-74.

Kobayashi O, Watanabe S, Hirose M, and Sato N (1996). Effects of transforming growth factors on the wound repair of cultured rabbit gastric mucosal cells. J Gastroenterol Hepatol 11:129-136.

Konturek PC, Ernst H, Brzozowski T, Ihlm A, Hahn EG, and Konturek SJ (1996). Expression of epidermal growth factor and transforming growth factor-alpha after exposure of rat gastric mucosa to stress. Scand J Gastroenterol 31:209216.

Laemmli UK, Beguin F, and Gujer-Kellenberger G (1970). A factor preventing the major head protein of bacteriophage T4 from random aggregation. $\mathrm{J} \mathrm{Mol} \mathrm{Biol} \mathrm{47:69-85.}$

Lau JL, Fowler JE Jr, and Ghosh L (1988). Epidermal growth factor in the normal and neoplastic kidney and bladder. J Urol 139:170-175.

Liu L, Turner JR, Yu Y, Khan AJ, Jaszewski R, Fligiel SE, and Majumdar AP (1998). Differential expression of EGFR during early reparative phase of the gastric mucosa between young and aged rats. Am J Physiol 275:G943-G950.

Martin BF (1972). Cell replacement and differentiation in transitional epithelium: A histological and autoradiographic study of the guinea-pig bladder and ureter. J Anat 112:433455.

Messing EM, Hanson P, Ulrich P, and Erturk E (1987). Epidermal growth factor: Interactions with normal and malignant urothelium. In vivo and in situ studies. J Urol 138:13291335.

Messing EM and Reznikoff CA (1987). Normal and malignant human urothelium: In vitro effects of epidermal growth factor. Cancer Res 47:2230-2235.

Miyazaki Y, Shinomura Y, Higashiyama S, Kanayama S, Higashimoto Y, Tsutsui S, Zushi S, Taniguchi N, and Matsuzawa $Y$ (1996). Heparin-binding EGF-like growth factor is an autocrine growth factor for rat gastric epithelial cells. Biochem Biophys Res Commun 223:36-41.

Nishida T, Nakamura M, Mishima H, and Otori T (1990). Differential modes of action of fibronectin and epidermal growth factor on rabbit corneal epithelial migration. J Cell Physiol 145:549-554.

Noguchi S, Yura Y, Sherwood ER, Kakinuma H, Kashihara N, and Oyasu R (1990). Stimulation of stromal cell growth by normal rat urothelial cell-derived epidermal growth factor. Lab Invest 62:538-544.

Peterson MG, Tanese N, Pugh BF, and Tjian R (1990). Functional domains and upstream activation properties of cloned human TATA binding protein. Science 248:16251630.

Puddicombe SM, Polosa R, Richter A, Krishna MT, Howarth $\mathrm{PH}$, Holgate ST, and Davies DE (2000). Involvement of the epidermal growth factor receptor in epithelial repair in asthma. FASEB J 14:1362-1374.

Radvanyi F, Christgau S, Baekkeskov S, Jolicoeur C, and Hanahan D (1993). Pancreatic beta cells cultured from individual preneoplastic foci in a multistage tumorigenesis pathway: A potentially general technique for isolating physiologically representative cell lines. Mol Cell Biol 13:42234232. 
Schlessinger J and Ullrich A (1992). Growth factor signaling by receptor tyrosine kinases. Neuron 9:383-391.

Schultz G, Rotatori DS, and Clark W (1991). EGF and TGF-alpha in wound healing and repair. J Cell Biochem 45:346-352.

Simeonova PP, Wang S, Toriuma W, Kommineni V, Matheson J, Unimye N, Kayama F, Harki D, Ding M, Vallyathan V, and Luster MI (2000). Arsenic mediates cell proliferation and gene expression in the bladder epithelium: Association with activating protein-1 transactivation. Cancer Res 60:34453453.

Stoll S, Garner W, and Elder J (1997). Heparin-binding ligands mediate autocrine epidermal growth factor receptor activation in skin organ culture. J Clin Invest 100:1271-1281.

Stoscheck CM, Nanney LB, and King LE Jr (1992). Quantitative determination of EGF-R during epidermal wound healing. J Invest Dermatol 99:645-649.
Tsao MS, Zhu H, and Viallet J (1996). Autocrine growth loop of the epidermal growth factor receptor in normal and immortalized human bronchial epithelial cells. Exp Cell Res 223:268-273.

Uchida K, Samma S, Rinsho K, Warren JR, and Oyasu R (1989). Stimulation of epithelial hyperplasia in rat urinary bladder by Escherichia coli cystitis. J Urol 142:1122-1226.

Wilson SE, Chen L, Mohan RR, Liang Q, and Liu J (1999). Expression of HGF, KGF, EGF and receptor messenger RNAs following corneal epithelial wounding. Exp Eye Res 68:377-397.

Zieske JD, Takahashi H, Hutcheon AE, and Dalbone AC (2000). Activation of epidermal growth factor receptor during corneal epithelial migration. Invest Ophthalmol Vis Sci 41: 1346-1355. 